\title{
SEQUÊNCIA DIDÁTICA PARA O ENSINO DE CINEMÁTICA COM VÍDEO ANÁLISE NA PERSPECTIVA DA TEORIA DE APRENDIZAGEM SIGNIFICATIVA
}

\author{
SANTOS R.P.* \\ Mestrado Nacional Profissional em Ensino de Física - MNPEF - Polo 15 - UFF/IFRJ \\ 27213-415 Volta Redonda - RJ, Brasil \\ Instituto Superior de Educação do Rio de Janeiro - ISERJ/FAETEC \\ 20270-003, Rio de Janeiro - RJ, Brasil \\ BALTHAZAR W. F. ${ }^{\dagger}$ \\ Instituto Federal de Educação, Ciência e Tecnologia do Estado do Rio de Janeiro, \\ Campus Volta Redonda, 27215-350 Volta Redonda - RJ, Brasil \\ HUGUENIN J. A. O. \\ Mestrado Nacional Profissional em Ensino de Física - MNPEF - Polo 15 - UFF/IFRJ \\ 27213-415 Volta Redonda - RJ, Brasil \\ Departamento de Física, Instituto de Ciências Exatas, Universidade Federal Fluminense, \\ 27213-415 Volta Redonda - RJ, Brasil
}

\begin{abstract}
Resumo
Neste trabalho apresentamos a elaboração de uma sequência didática para o ensino de cinemática no ensino médio explorando vídeo análise através do software Tracker. Para tanto, realizamos a filmagem de seis movimentos diferentes (movimento retilíneo uniforme e acelerado, lançamento, horizontal e oblíquo) produzidos por instrumentos do Laboratório Didático do curso de graduação em física (PASCO e CIDEPE) do Instituto de Ciências Exatas da Universidade Federal Fluminense (UFF) através de equipamento de filmagem de alta resolução da TV Universitária TVR - UFF. A produção destes filmes possibilitou maior precisão na geração dos movimentos e qualidade na imagem, resultando em maior qualidade no processo de vídeo análise. A sequência foi produzida tendo como referencial teórico a Teoria de Aprendizagem Significativa. Os resultados da aplicação da sequência em uma escola pública do Estado do Rio de Janeiro são discutidos levando-nos a acreditar que a sequência didática produzida seja potencialmente significativa.
\end{abstract}

Palavras-chave: Vídeo análise, cinemática, aprendizagem significativa.

\footnotetext{
*rps71@ hotmail.com

†wagner.balthazar@ifrj.edu.br

†huguenin@if.uff.br
} 


\begin{abstract}
In this work we present a didactic sequence to teach kinematics concepts in high school level by means video analysis through the Tracker software. We produced six movies of different movements (uniform, accelerated, vertical, horizontal and oblique launch) by using materials of under graduation Physcis Course of Instituto de Ciências Exatas of the Universidade Federal Fluminense (UFF) and a high definition equipments of TV Universitária TVR - UFF. The movies production improved the quality od the movements and the precision in the video analysis. The sequence was prepared based in the Meaningful Learning Theory. The results of the sequence application in a public school of Rio de Janeiro State is presented and lead us to believe that it is a potentially Meaningful sequence.
\end{abstract}

Keywordds: Video analysis, kinematics, Meaningful Learning

\title{
1 Introdução
}

No mundo atual, temos convivido com um grande avanço tecnológico que naturalmente modifica nossa sociedade e a forma com que interagimos com o mundo ao redor [1]. Nesse cenário, dispositivos eletrônicos têm papel de protagonista nas relações sociais e de trabalho, principalmente entre os jovens. Por isso, é natural que esses dispositivos estejam presentes no contexto da escola, uma vez que quase todos os jovens possuem ou têm acesso, por exemplo, a smartphones e computadores. Dessa forma, é fundamental pensar nesses dispositivos como meios de interação no processo ensino-aprendizagem.

No contexto da pesquisa em ensino de física, há muitos anos o uso de tecnologias de informação e comunicação (TIC's), vêm sendo estudadas e propostas [2, 3, 4]. Com o aumento do acesso de alunos a tais tecnologias várias propostas têm surgido com objetivo de utilizá-las em atividades práticas em sala de aula visando à aprendizagem em física. Podemos mencionar, simulações e modelagens computacionais [5, 6], experimentos virtuais [7, 8, 9, 10] e vídeo análise [11, 12, 13]. Esse esforço parece convergir com a retomada da experimentação na escola, uma vez que esse material é de fácil acesso e permite que experimentos sejam feitos mesmo sem a presença de um laboratório didático tradicional. Isso converge para o descrito nos Parâmetros Curriculares Nacionais do Ensino Médio (PCNEM), atribuindo a experimentação uma maior abrangência para além das situações convencionais de experimentação em laboratório. Nesse sentido, é possível trabalhar, por exemplo, com dispositivos eletrônicos e materiais de baixo custo. O que de fato importa é que competências estão sendo promovidas com as atividades desenvolvidas [14]. Diante desse cenário, é preciso pensar para além dos experimentos e da contribuição de novos materiais didáticos. Por isso, novas propostas têm surgido associando esses materiais a diferentes abordagens de ensino, cujo objetivo é um "produto" que atenda a necessidade do professor em condições reais de sala de aula. 
No que se refere ao tema específico que trataremos nesse trabalho, a Cinemática, um assunto que historicamente é de grande importância para a física, há muito foi apontado que seu ensino fica geralmente dedicado a aplicação de fórmulas, muitas vezes em detrimento de outros importantes conceitos físicos da Mecânica que são simplesmente deixados de lado [15]. Se adicionarmos a isso, um ensino fundamentado no modelo clássico da narrativa, onde o aluno ocupa uma condição passiva, de receber o conhecimento do professor [16], e da ausência de atividades experimentais que permitam a discussão dos fenômenos, temos um cenário em que o aprendizado em física é prejudicado, uma vez que não passa de um conjunto de regras ou operações matemáticas que o aluno aprende para fazer uma prova. Nesse sentido, aliar a experimentação a uma participação ativa do aluno, de forma que a aprendizagem tenha significado, é uma perspectiva que agrada e pode colaborar para um ensino de física que faça sentido.

Atualmente, muitos trabalhos têm sido propostos para o ensino de cinemática, podemos citar propostas alternativas [17], modelagem computacional [18] e trabalhos envolvendo uma importante ferramenta vídeo análise, o software Tracker [19, 20]. Neste trabalho, estamos interessados nessa última ferramenta. No entanto, utilizar as TIC's sem uma estratégia clara pode não mudar o quadro da abordagem matematizada, calcada no ensino narrativo que culmina com o aprendizado mecânico. Em contraposição, podemos lançar mão de teorias de aprendizagem que levam em conta uma série de fatores essenciais ao aprendizado. Entre elas está a Aprendizagem Significativa de Ausubel [21]. Nessa teoria, o aprendizado acontece quando uma nova informação adquire significado para quem aprende. Para tal, a informação deve estar ancorada em conceitos e ideias relevantes e pré-existentes na estrutura cognitiva do aluno, de forma que haja uma interação entre conhecimentos novos e os já existentes [22]. Nesse sentido, o novo ganha significado e o já existente é ressignificado ou persiste na estrutura cognitiva do aprendiz. Naturalmente, se num processo educacional o objetivo final é a aprendizagem significativa, faz-se necessário a existência de sequências didáticas que potencializem esse tipo de aprendizagem, por isso, essa teoria embasa a construção de sequências didáticas também das chamadas unidades de ensino potencialmente significativas -UEPS [23].

Neste trabalho apresentamos uma proposta capaz de abordar um tema importante da física, a cinemática, através de uma sequência didática baseada na Teoria de Aprendizagem Significativa (TAS). A sequência une vídeo análise e experimentação. Apresentaremos na seção 2 uma breve descrição da TAS e a potencialidade do uso de TIC's nesta abordagem. Na seção 3, apresentaremos a sequência didática, que teve como ferramenta para tomada de dados o software de vídeo análise conhecido como TRACKER. $\mathrm{Na}$ seção 4 apresentaremos as etapas de aplicação da sequência didática em turmas do ensino médio. Na seção 5 discutiremos os resultados das respostas dadas pelos alunos durante a aplicação da sequência. Finalmente, na seção 6 organizamos as principais conclusões do trabalho.

\section{Aprendizagem Significativa e TIC's}

A Teoria de Aprendizagem significativa (TAS) de David Ausubel [21] está baseada na ideia de que o processo ensino-aprendizagem ocorre através da transformação da estrutura cognitiva do aprendente. O principal fator a ser considerado neste processo, segundo Ausubel, é o conhecimento prévio do aluno, também chamado de subsunçor. Um subsunçor é entendido como uma estrutura de conhecimento de abrangência variável com a qual a um novo conceito a ser aprendido interage [24]. Nesta interação, o 
novo conceito amplia a abrangência do antigo subsunçor, ampliando as possibilidades para aprendizagem de novos conceitos, ainda mais complexos. Por exemplo, quando um aluno vai estudar queda livre dos corpos ele já traz consigo o conhecimento (subsunçor) de que os corpos caem se abandonados. Logo, durante tal estudo ele associa a força peso como a causa da queda dos corpos, e o subsunçor fica mais abrangente: ele sabe que os corpos caem e o motivo pelo qual isso acontece. Com este novo subsunçor fica mais fácil entender a decomposição do movimento de projéteis, por exemplo. Vale destacar que a interação entre os subsunçores e um novo conhecimento é não-arbitrária, ou seja, o novo conhecimento não dialoga com qualquer subsunçor, mas com aqueles necessários/importantes para o aprendizado do assunto a ser ensinado.Por este motivo, sequências didáticas escritas com base na TAS deve buscar organizar os subsunçores relevantes através dos chamados Organizadores Prévios (OP)[24], que são materiais/atividades preparados com a intenção de aflorar no aluno o subsunçor adequado para o novo conhecimento. No exemplo acima, um organizador prévio interessante seria segurar um objeto e perguntar o que acontecerá quando o soltarmos. Essa pergunta remete a experiência prévia de que os corpos caem. Muitas das vezes, os OP ajudam a cobrir lacunas na formação inicial do aprendente oferecendo a possibilidade de construção de uma ponte para o novo aprendizado no caso de não haver no aluno o conhecimento prévio necessário ao estudo daquele conteúdo. Usando a imagem anterior, apenas para ilustrar a importância dos OP, caso o aluno não soubesse previamente que corpos caem ao serem abandonados, ele poderia visualizar a queda e perceber, pela repetição, que os corpos caem. Desta forma, este OP (experiência de abandonar um corpo) supriria a ausência do subsunçor no aluno. Como se vê, o material a ser utilizado tem grande peso no processo de ensino de forma a potencializar a aprendizagem significativa. Além disto, o processo é também não-literal já que o aprendente dá um significado pessoal ao novo aprendizado, modificando subsunçores existentes ou criando novos. Esta significação pessoal requer envolvimento do aluno, pré-disposição ao aprendizado. Desta forma, podemos sumarizar os pontos de maior representatividade para a ocorrência da aprendizagem significativa da seguinte forma: a) Conhecimentos prévios, b) pré-disposição ao aprendizado e, c) Material potencialmente significativo. Estes três pontos formam a base para a construção de sequências didáticas baseadas na TAS, como é o caso das Unidades de Ensino Potencialmente Significativas (UEPS) [23]. Na apresentação da sequência didática que propomos buscaremos evidenciar estes aspectos.

Construir uma sequência didática potencialmente significativa, parte de descobrir uma forma que facilite a organização prévia dos subsunçores e ajude no aumento da pré-disposição dos alunos ao aprendizado. É imprescindível usar uma linguagem acessível a faixa etária do aluno, além de explorar temas de interesse. Neste tocante, o uso de Tecnologias de Informação e Comunicação (TIC's) tem um importante papel para o ensino de uma geração de estudantes conhecida como "Geração Digital". Como dito na seção anterior, Os estudantes do ensino médio, atualmente, tem facilidade de lidar com instrumentos digitais, aplicativos, jogos, tendo incorporado em sua linguagem assuntos relacionados ao uso de mídias. Desta forma, simuladores e aplicativos podem ser considerados fortes aliados para construção de uma sequência potencialmente significativa. Em particular, o uso de vídeo análise através do TRACKER tem encontrado várias formas de uso no ensino de Física, sendo ferramenta de grande potencial significativo. Na próxima seção apresentamos uma proposta para o ensino de cinemática através da vídeo análise através de uma sequência didática baseada na TAS. 


\section{Sequência Didática}

Algumas propostas para o uso de vídeo análise no ensino de física baseiam-se na ideia dos alunos filmarem movimentos com smartphones ou câmeras e analisarem seus próprios vídeos [11, 27, 28]. Esta estratégia tem um grande poder de envolvimento e mobilização para participação dos alunos pela sua ludicidade. Porém, há dois problemas que não podem ser desprezados. Primeiro, a qualidade dos filmes produzidos de forma muito caseira pode empobrecer os resultados da análise, seja pela qualidade e resolução dos filmes, seja pela dificuldade em produzir o movimento de forma correta. O segundo problema é a carga horária reduzida da disciplina Física na grade escolar, sobretudo na rede pública de ensino. Este fato inibe a realização de propostas que exigem maior tempo de execução. Além disso, há Estados da federação que possuem leis que impedem o uso de smartphones e telefones celular pelos alunos. Nestes casos, a vídeo análise só é viável com vídeos previamente produzidos.

Apresentamos neste trabalho um produto educacional baseado na TAS, desenvolvido durante uma dissertação de mestrado profissional em ensino de física no Polo 15 do MNPEF, em Volta Redonda - RJ.

O produto educacional é uma sequência didática contendo cinco componentes: $1^{\circ}$ - seis filmes de movimento obtidos com alta resolução; $2^{\circ}$ - um roteiro didático para o aluno (questionário prévio) que acreditamos ser o principal organizador prévio da sequência didática; $3^{\circ}$ - roteiro de atividades com vídeo análise que o professor que desejar aplicar a sequência pode imprimir ou projetar. Toda a sequência com perguntas e espaço para respostas está disponível neste roteiro. Esta parte explora o uso de tecnologias como elemento que possa ajudar a aumentar a pré-disposição ao aprendizado do aluno; $4^{\circ}$ - um texto instrucional para a sistematização dos conteúdos; e $5^{\circ}$ - um manual de utilização da sequência didática com todos os detalhes, passo a passo, para aplicação da sequência e de como o software Tracker pode ser instalado e utilizado, todas as atividades da sequência comentadas, salientando os resultados esperados e contento dicas de possíveis desafios que o professor poderá encontrar durante a aplicação. Todo este material que compõe o produto educacional pode ser obtido gratuitamente no endereço disponível na Ref.[26].

Os seis filmes de movimentos foram produzidos nos estúdios da TV Universitária NOME, com equipamentos de grande resolução digital. Os movimentos filmados são a - movimento retilíneo uniforme, b - movimento retilíneo acelerado, c - movimento retilíneo retardado, d - queda livre, e - lançamento horizontal, e f - lançamento oblíquo.

Para produção dos movimentos foram usados trilhos de movimento da PASCO (para movimento retilíneo), lançadores de projéteis oblíquo e horizontal da CIDEPE (para lançamento horizontal e oblíquo), todos equipamentos do Laboratório Didático do Curso de Graduação em Física do Instituto NOME DA INSTITUICAO. Os vídeos estão disponibilizados e os professores podem usá-los em suas aulas, independente de executar a sequência didática proposta.

Podemos dividir sequência didática em três partes:

Parte 1 - Conhecimentos prévios: Esta primeira etapa utiliza o $1^{\circ}$ e $2^{\circ}$ componentes do produto educacional descrito acima. Para iniciar a sequência os alunos assistem a todos vídeos e respondem a um a questionário prévio, que consiste na mesma questão para cada um dos vídeos: o aluno deve indicar com 


\begin{tabular}{|c|c|c|c|c|c|c|c|c|}
\hline $\mathrm{C} 1$ & $\mathrm{C} 2$ & $\mathrm{C} 3$ & $\mathrm{C} 4$ & $\mathrm{C} 5$ & $\mathrm{C} 6$ & $\mathrm{C} 7$ & $\mathrm{C} 8$ & $\mathrm{C9}$ \\
\hline $\mathrm{a}=0$ & $\rightarrow$ & $\leftarrow$ & $\nearrow$ & $\nwarrow$ & $\uparrow$ & $\downarrow$ & $\downarrow$ & $\searrow$ \\
\hline
\end{tabular}

Figura 1: Tela do Tracker para análise do lançamento oblíquo. Podemos observar O lançador de projéteis da CIDEPE, as marcações das posições da análise do movimento (em vermelho). Do lado direito da imagem temos os gráficos das direções $x$ (superior) e y (central).

uma seta a direção da aceleração do móvel, caso exista. No roteiro há espaço indicado de onde os alunos podem fazer as setas representativas para cada vídeo. Caso o professor não imprima este roteiro, ele pode pedir que os alunos façam esta atividade projetando as perguntas e respondendo em uma folha branca. Não é feita a vídeo análise neste momento, e os alunos respondem a esta questão para cada vídeo com base em seu conhecimento prévio e em sua observação. O professor apenas chama a atenção para verificarem como varia a posição com o tempo. Estas respostas não são corrigidas. Elas podem ficar com os alunos ou o professor pode recolher para acompanhar a evolução do aluno ou dividir melhor o tempo da segunda parte, dando mais ênfase às questões que apresentaram maior erro. Em nosso caso, o material foi recolhido para analisarmos o resultado da aplicação da sequência. Esta atividade foi planejada para ser executada em um tempo de 50 min. O questionário prévio abordou questões que apresentam, frequentemente, concepções alternativas, visando que os alunos ficassem frente a uma situação de confronto entre o que ele respondeu nesta etapa e na conclusão das atividades.

Parte 2 - Vídeo análise: Após a observação dos vídeos, o professor faz a vídeo análise dos filmes mostrados anteriormente. Com a observação desta análise, uma série de perguntas com espaço para respostas dos alunos após a vídeo análise contidas no roteiro do $3^{\circ}$ componente do produto vai construindo os conceitos básicos da cinemática. Após respostas dos alunos, o professor discute com a turma em grande grupo para fechar uma conclusão sobre a questão, com base na vídeo análise. Após as questões formadoras, revisitamos os vídeos do questionário prévio, fazendo rapidamente a vídeo análise, permitindo que os alunos confrontassem as respostas dadas anteriormente com a resposta dada após a realização das atividades. Outros vídeos são analisados, sendo que em cada um deles é mostrado o gráfico da posição em função do tempo. A Figura 1 ilustra a análise feita para o lançamento oblíquo. É possível observar a trajetória do móvel através das marcações de posição da análise em vermelho e também o gráfico da posição em função do tempo( à direita na imagem).

Caso exista a possibilidade de os alunos usarem um laboratório de informática, eles podem manipular o Tracker, o que aumentaria a participação deles, por um lado, e demandaria mais tempo para aplicação, 
de outro. O professor chama a atenção do gráfico feito pelo software e os convida a responder novamente a pergunta da primeira parte. Os alunos tem um ficha para colocarem suas respostas após a vídeo análise. Ele tem a chance de rever o que respondeu no questionário prévio, quando só assistiu ao vídeo, sem a realização da vídeo análise do filme. Até aqui a intervenção do professor é somente mediadora. Depois que a turma termina de responder, o professor inicia uma discussão com um grande grupo, pedindo respostas, questionando ideias contraditórias e encaminhando a discussão para a resposta correta à questão. Os alunos são convidados, então, a escreverem logo abaixo das respostas anteriores as conclusões da discussão, em local próprio no material do aluno. Aqui espera-se que a turma confronte a resposta cientificamente aceita, como as duas respostas dadas por ele anteriormente. Esta atividade foi planejada para ser feita em três tempos de 50 min. (professor projetando a vídeo análise).

Parte 3 - Sistematização: Por fim, os alunos são apresentados a um material instrucional na forma de texto $\left(4^{\circ}\right)$, elaborado exclusivamente para sequência, uma vez que explora os vídeos analisados. Nesta parte é que são introduzidas as equações da cinemática, enfim, a formalização dos conceitos, são apresentados exercícios conceituais e também quantitativos.Esta etapa foi pensada para ser executada em dois tempos de $50 \mathrm{~min}$.

O tempo total estimado para aplicação é de seis tempos de $50 \mathrm{~min}$, em bom acordo com a realidade de carga horária da disciplina de Física no ensino médio. Evidentemente, o professor pode adaptar o tempo de aplicação em suas turmas conforme a necessidade e disponibilidade de tempo. A redução do tempo pode ser obtida diminuindo-se o número de vídeos trabalhados. Vale destacar que o professor pode usar a sequência para movimento retilíneo (1D) e no plano o (2D) de forma independente.

Todos os detalhes da sequência didática, com guia passo a passo de aplicação, inclusive com tutoriais para uso do TRACKER, endereço dos vídeos, questionários dos alunos e material instrucional, pode ser obtida no Manual de Utilização está no $5^{\circ}$ componente do produto educacional que pode ser obtido gratuitamente no endereço da Ref.[26].

\section{Aplicação}

A sequência didática foi aplicada para duas turmas de primeira série e duas turmas de segunda série do Instituto de Educação Superior do Rio de Janeiro - ISERJ, da rede FAETEC. Ao todo participaram 60 alunos, sendo 29 de primeira série e 31 de segunda série do ensino médio. A escolha de aplicação da sequência para a segunda série, que estudou o conteúdo no ano anterior, teve por objetivo comparar o resultado desta turma com o obtido para os alunos do primeiro ano, que estudavam este assunto no nível médio pela primeira vez. Dessa forma, verificamos se a sequência possibilita um nível de aprendizado satisfatório, bem como o papel dos subsunçores, haja visto que os alunos de segunda série já haviam estudado formalmente estes conceitos.

O planejamento pôde ser cumprido dentro do tempo previsto, não sendo necessário acelerar a execução das tarefas. Isto se deveu, em grande parte, ao engajamento dos alunos nas atividades. Vamos apresentar um breve relato da aplicação de cada parte da sequência. 


\subsection{Relato dos encontros}

Primeira parte: conforme planejado, a parte inicial durou cerca de $50 \mathrm{~min}$ (1 tempo de aula de 50 minutos), tanto para turmas de primeira série quanto para as turmas de segunda série. Ao assistirem ao vídeos os aluno respondiam o questionário prévio. Foi possível observar durante a primeira parte da sequência que as turmas ficaram surpresas com esse tipo de aula, pois foram colocados em situação de protagonistas, manifestando suas dúvidas e discutindo suas respostas com os colegas. Para avaliar as respostas dadas ao questionário prévio, recolhemos o material respondido dos alunos.

Segunda parte: iniciou-se esta etapa com apresentação do software Tracker e suas principais funcionalidades. Passamos, assim, a mostrar a análise dos vídeos. Os alunos responderam a questão no campo indicado no caderno do aluno (parte do aluno na sequência didática, conforme Ref.[26]), tendo a chance de rever a resposta que deu no questionário prévio. Depois de pequena pausa para as respostas, realizou-se discussão em grande grupo, a partir da qual, dialogando com a turma, foi construída uma conclusão sobre a resposta correta. Os alunos participaram ativamente das atividades, mostrando grande envolvimento.

A revisita aos vídeos do questionário prévio mostrou que os alunos ficaram surpresos e muito satisfeitos em comparar a resposta final sobre aceleração. Os alunos perceberam que a análise do vídeo facilitou a identificação do momento usando o software Tracker.

Terceira parte: no último encontro, foi apresentado o material instrucional que guiou a sistematização do aprendizado através de uma aula expositiva dialogada. Em relação a uma aula expositiva tradicional, as atividades anteriores nos dois primeiros encontros possibilitaram uma participação efetiva dos alunos nesta atividade mais formal. Foi possível observar que este último encontro se tratou mesmo de uma sistematização, pois, durante os diálogos da aula expositiva, para grande parte dos conceitos, os alunos mostraram ter adquirido boa compreensão.

\section{Resultados}

O resultado da aplicação foi estudado à luz das respostas dadas pelos alunos nos roteiros de atividades fornecidos aos alunos na aplicação da sequência, que foram avaliadas seguindo o método de análise de conteúdo [25]. Este método consiste em obter categorias de respostas, que podem ser previamente estabelecidas ou determinadas posteriormente a medida que aparecem nos textos analisados. Depois categoriza-se os textos conforme a frequência em que estas categorias são encontradas nos textos. Em nosso trabalho, para o questionário prévio (componente 2 do produto educacional) tomamos como categorias todas as respostas diferentes que encontramos. Para o estudo das atividades de vídeo análise (componente 3 do produto educacional) escolhemos categorias previamente estabelecidas no que diz respeito ao atingimento das metas de cada questão.

$\mathrm{Na}$ aplicação do questionário prévio os alunos foram convidados a desenhar uma seta mostrando direção e sentido da aceleração do móvel em cada um de seis vídeos de movimento, quando houvesse aceleração e $a=0$ quando eles entendessem que o movimento não era acelerado. Lembramos que nesta etapa foi apenas mostrado o vídeo, sem a vídeo análise. Para análise de conteúdo do questionário prévio levantamos as possíveis respostas dadas e encontramos nove tipos diferentes de respostas que usamos como categoria. As categorias de respostas encontradas são mostradas na Figura 2. 


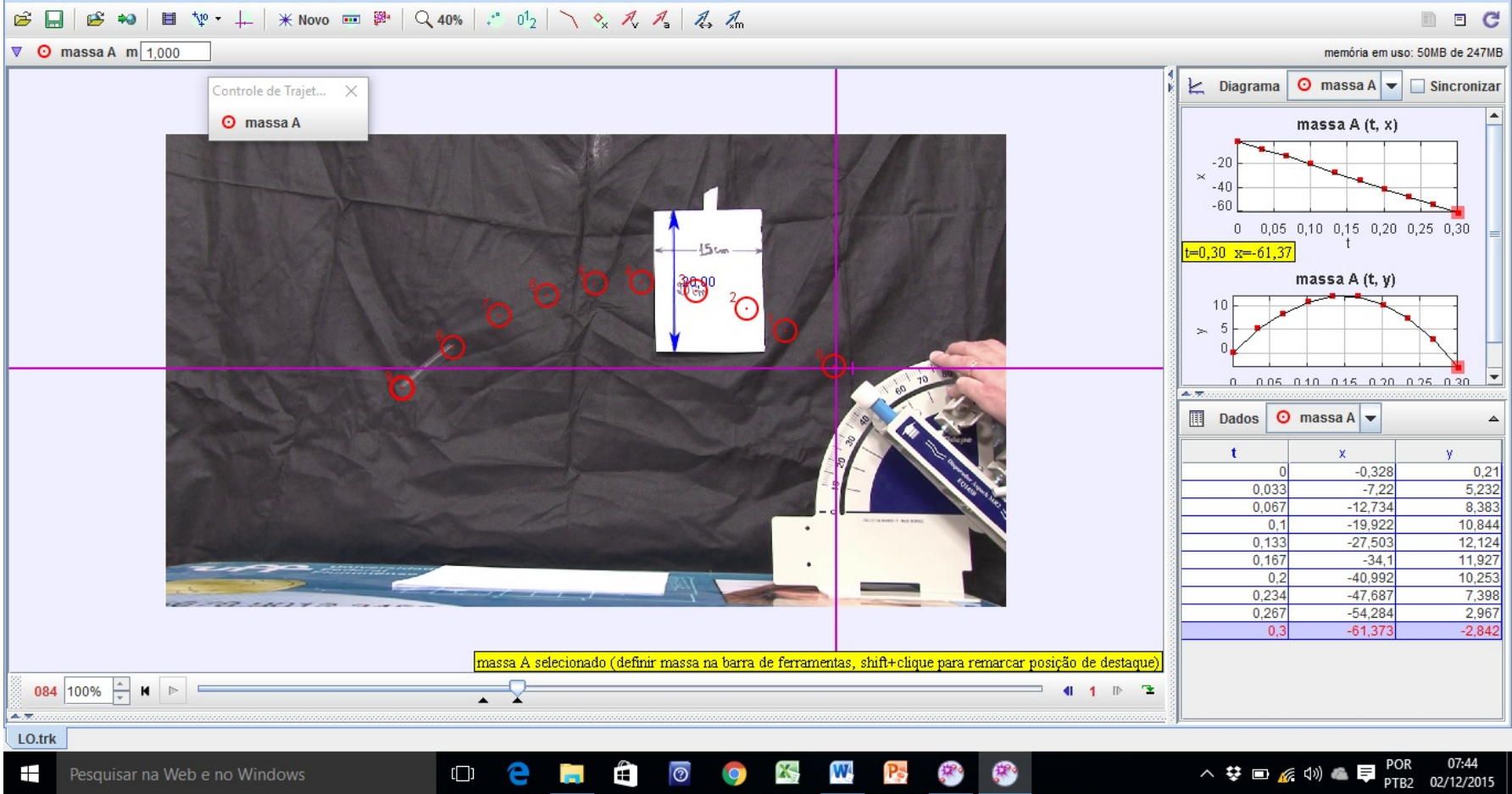

Figura 2: Categorias de respostas encontradas na atividade de conhecimentos prévios. 
Vamos discutir o resultado para três dos vídeos mostrados na Parte 1 da sequência, ou seja, no questionário prévio.

O primeiro vídeo mostrado foi o de um móvel em movimento retilíneo uniforme deslocandose para a direita. Entre as turmas de primeira série as categorias observadas nas resposta foram $C 1(6,9 \%), C 2(89,6 \%), C 6(3,5 \%)$. A grande maioria mostrou ter o raciocínio aristotélico, respondendo de acordo com a concepção alternativa em que a aceleração é diretamente proporcional à velocidade, apontando para o sentido do movimento. Para este movimento a categoria que representa o pensamento aristotélico é a $C 2$. Apenas $6,9 \%$ dos alunos acertaram a reposta indicando que a aceleração é nula neste movimento $(C 1)$. Considerando agora as turmas de segunda série, que tiveram no ano anterior o ensino formal deste conteúdo seguindo a metodologia tradicional, observamos as categorias $C 1(25,8 \%), C 2(64,5 \%), C 4(6,4)$, e $C 6(3,3 \%)$. A número de respostas corretas $(C 1)$ aumentou como o esperado para este grupo de alunos, mas entre eles $64,5 \%$ respondeu conforme a concepção alternativa.Ou seja, para os alunos que já viram o conteúdo na forma tradicional, para quem se esperava demostrar a existência de conhecimentos prévios mais profundos, o resultado ainda apresenta baixo nível de compreensão cientificamente correta. Este resultado, infelizmente, está de acordo com estudos que apontam para o fato do ensino mecânico, baseado na narrativa, não é assimilado pela estrutura cognitiva dos alunos. Eles repetem na prova o que o professor espera e simplesmente não muda sua concepção de mundo. Em outras palavras, não é significativo [23]. As respostas relativas as categorias $C 4$ e $C 6$ que apareceram destoaram demais das respostas esperadas e pela baixa frequência acreditamos ser respostas descompromissadas com a realização da atividade.

O segundo vídeo mostrado foi o de um móvel em movimento retilíneo uniformemente acelerado para esquerda. Para primeira série, tivemos $75,9 \%$ dos alunos que deram a resposta correta, ou seja, a categoria $C 3$. Outras repostas encontradas foram $C 1(13,8 \%), C 2(6,9 \%), C 8(3,4)$. Para segunda série o resultado observado foi $96,8 \%$ de repostas corretas $(C 3)$ e 3,2\% respondeu $C 8$. Neste caso, a aceleração coincide com o sentido do movimento, o que contribuiu para os acertos através do conceito calcado na concepção alternativa.

Esta interpretação é corroborada pelo resultado do terceiro vídeo mostrado em que temos um movimento retilíneo uniformemente retardado para a direita. Para as turmas de primeira série a maioria das respostas $(75,8 \%)$ ficou concentrada no sentido do deslocamento do corpo $(C 2)$, havendo apenas $6,9 \%$ de respostas corretas $(C 3)$.

Para a segunda série o resultado foi mais equilibrado com $51,6 \%$ respondendo $C 2$ e $45,1 \%$ respondendo corretamente $(C 3)$.

Desta forma, ficou evidente a prevalência de concepções alternativas sobre o conceito de aceleração mesmo entre alunos que já realizaram estudos formais deste conteúdo. Uma discussão detalhada sobre as respostas de todos os vídeos mostrados pode ser vista na Ref.[26].

Vamos apresentar agora a análise de uma atividade da Parte 2 da sequência didática, onde os filmes são apresentados com a vídeo análise. Para estas atividades a análise foi feita com base em quatro categorias pré-estabelecidas que estratificam o grau de correção das respostas dadas pelos alunos. Cada resposta dada a pergunta do roteiro de atividades foi classificada como CERTA, PARCIALEMENTE CERTA, ERRADA ou EM BRANCO.

Vamos discutir a atividade que busca mostrar a relação da velocidade do móvel com a distância 
percorrida, levando a inferir se o movimento é acelerado ou não. A intenção foi verificar se alunos seriam capazes de classificar o movimento olhando apenas para as posições marcadas no Tracker, o que é equivalente a uma foto estroboscópica. Eles deveriam perceber se a velocidade estava aumentando, diminuindo ou permanecendo constante. Esta atividade coloca o aluno em uma posição de confronto com as respostas dadas na atividade de conhecimento prévio. A questão proposta foi "Para este movimento analisado, a velocidade do corpo em cada intervalo de tempo, aumenta, diminui ou permanece constante? Faça essa análise no eixo X (eixo horizontal)." Seguindo as etapas estabelecidas, o professor realizou a vídeo análise e pediu aos alunos que, observando os gráficos gerados, dessem sua resposta. Após um tempo para responderem, o professor realizou uma discussão em grande e grupo salientando os principais pontos da vídeo análise, comparando respostas de diferentes alunos, questionando aquelas que se mostravam erradas. Depois desta discussão o aluno escreve sua "conclusão" em espaço específico no roteiro de atividades. Com isso, após a discussão e comparação de respostas dos colegas e das argumentações do professor, ele tem a oportunidade de rever sua resposta para questão e espera-se que neste ponto ele possa chegar a resposta correta.

Vamos discutir o resultado obtido para o estudo do vídeo de lançamento oblíquo. Para o movimento horizontal temos velocidade constante. Após a realização de todas as etapas para este vídeo tivemos entre os alunos da primeira série $72,5 \%$ de respostas CERTAS, 17,2\% de respostas ERRADAS e 10,3\% de repostas EM BRANCO. Entre os alunos de segunda série o resultado obtido foi 87,0\% de respostas CERTAS, 6,5\% de respostas ERRADAS e 6,5\% de repostas EM BRANCO. Como podemos ver, obtivemos um alto índice de alunos que alcançaram o objetivo com a atividade, com vantagem para os alunos de segunda série, que já haviam estudado formalmente o conteúdo e, em tese, tinham subsunçores mais elaborados. O percentual de respostas EM BRANCO está de acordo com as respostas dadas com pouco cuidado, de forma descompromissada, na atividade de conhecimentos prévios. Não é absurdo supor que se trata de não comprometimento com a atividade, antes de ineficácia do método. Os alunos que não alcançaram o objetivo nesta atividade ( $27,6 \%$ na primeira série e $13,0 \%$ na segunda série) ainda terão a oportunidade de aprendizado do conceito na Parte 3 da sequência, ou seja, na etapa de sistematização através do material instrucional desenvolvido e a aula expositiva-dialogada. Os alunos que atingiram o objetivo na Parte 2 da sequência poderão sedimentar ainda mais o conceito nesta terceira parte, consolidando a ideia central, modificando seus subsunçores. Uma análise completa de todas as atividades realizadas na sequência pode ser vista na Ref.[26].

\section{Conclusões}

Em suma, apresentamos a concepção de uma sequência didática para ensino de cinemática através de vídeo análise sob uma perspectiva da aprendizagem significativa. Produzimos vídeos de movimentos variados através de equipamentos dos laboratórios didáticos do curso de física de forma a termos movimentos controlados conforme desejado. Os vídeos foram produzidos com equipamentos de alta resolução da TV universitária TVR-UFF, dando qualidade às análises realizadas com o Tracker. A sequência é compostas de três etapas: atividades de conhecimento prévio, vídeo análise e sistematização. As duas primeiras etapas possuem cadernos de atividades para alunos e manual de aplicação para o professor. A 
terceira etapa conta com um material instrucional desenvolvido com exclusividade para esta sequência que explora linguagem introduzida na vídeo análise. Todo o material, incluindo os vídeos podem ser obtidos no endereço da Ref.[26] para uso direto do professor. A aplicação da sequência mostrou que o envolvimento dos alunos com a aula foi muito acima daquele observado em uma aula tradicional, de forma que acreditamos que a sequência ajuda a aumentar a pré-disposição ao aprendizado nos alunos. As atividades de vídeo análise buscam confrontar as respostas dadas na primeira etapa, valorizando o conhecimento prévio do aprendente. Os resultados mostraram alto índice de aproveitamento dos alunos. Pelo exposto, acreditamos que a sequência aqui apresentada tem grande potencial para propiciar uma aprendizagem significativa dos conceitos de cinemática.

\section{Referências}

[1] PONTE, C., Uma geração digital? A influência familiar na experiência mediática de adolescentes. Sociologia, Problemas e Práticas, n. 65, p. 31-50, 2011.

[2] PIRES, M.A. e VEIT, E.A., Tecnologias de Informação e Comunicação para ampliar e motivar o aprendizado de Física no Ensino Médio, Revista Brasileira de Ensino de Física, v. 28, n. 2, p. 241 248, 2006.

[3] PEIXOTO, J. e ARAÚJO C.H.S., Tecnologia e educação: algumas considerações sobre o discurso pedagógico contemporâneo, Educ. Soc., Campinas, v. 33, n. 118, p. 253-268, 2012.

[4] MÉNDEZ, D. e SLISKO, J., Software Socrative and smartphones as tools for implementation of basic processes of active physics learning in classroom: An initial feasibility study with prospective teachers. European Journal of Physics Education, v. 4, n. 2, 2013.

[5] ARANTES, A.R., MIRANDA, M.S., STUDART, N., Objetos de aprendizagem no ensino de física: usando simulações do PhET, Física na Escola, v. 11, n. 1, 2010.

[6] DORNELES, P.F.T., ARAUJO. I.S., VEIT, E.A., Simulação e modelagem computacionais no auxílio à aprendizagem significativa de conceitos básicos de eletricidade: Parte I - circuitos elétricos simples, Revista Brasileira de Ensino de Física, v. 28, n. 4, p. 487-496, 2006.

[7] NORA, M.F., MAIDANA, L., SEVERINO, E., Barros, S., Senhora, G., Vanin, V.R., O laboratório virtual: Uma atividade baseada em experimentos para o ensino de mecânica, Revista Brasileira de Ensino de Física, v. 35, n. 4, 45032013.

[8] YAMAMOTO, I., BARRETH, V.B., Simulações de experiências como ferramenta de demonstração virtual em aulas de Teoria de Física, Revista Brasileira de Ensino de Física, São Paulo, v. 23, n. 2, p. 215-225, 2001.

[9] KUHN, J. e VOGT, P., Smartphones as experimental tools: Different methods to determine the gravitational acceleration in classroom physics by using everyday devices. European Journal of Physics Education, v. 4, n. 1, 2013. 
[10] VIEIRA, L. P.; LARA, V. O. M.; AMARAL, D. F., Demonstraçao da lei do inverso do quadrado com o auxılo de um tablet/smartphone. Revista Brasileira de Ensino de Fisica, v. 36, n. 3, p. 3505, 2014.

[11] FERNANDES, A.C.P., AULER, L.T.S., HUGUENIN, J.A.O., BALTHAZAR, W.F., Efeito Doppler com tablet e smartphone, Revista Brasileira de Ensino de Física, vol. 38, nº 3, e3504 2016.

[12] CAVAlCANTE, M. A., PEÇANHA, R., TEIXEIRA, A. C., Ondas estacionárias em cordas e determinação da densidade linear de um fio, Revista Brasileira de Ensino de Física, v. 35, 2013.

[13] WRASSE, A. C., ETCHEVERRY, L. P., MARRANGJELLO, G. F., ROCHA, F. S., Investigando o impulso em crash tests utilizando vídeo-analise, Revista Brasileira de Ensino de Física, v. 36, 2014.

[14] BRASIL., Parâmetros Curriculares Nacionais do Ensino Médio. Ministério da Educação e Cultura, Brasília, pág. 81, 2000.

[15] LARIUCCI, C. e NAPOLITANO, H. B., Alternativa para o ensino da cinemática - Interação, Revista Faculdade de Educação, UFG, v. 26, 2001.

[16] MOREIRA, M. A., Abandono da narrativa, ensino centrado no aluno e aprender a aprender criticamente. Conferência proferida no II Encontro Nacional de Ensino de Ciências da Saúde e do Ambiente, Niterói, RJ, 12 a 15 de maio de 2010 e no VI Encontro Internacional e III Encontro Nacional de Aprendizagem Significativa, São Paulo, SP, 26 a 30 de julho de 2010.

[17] SOUZA, P. V. S. e DONANGELO, R., Velocidades média e instantânea no Ensino Médio: uma possível abordagem. Revista Brasileira de Ensino de Fsica, v. 34, n. 3, 3503, 2012.

[18] ARAUJO, I. S. VEIT, E. A. e MOREIRA, M. A., Atividades de modelagem computacional no auxílio a interpretaÇão de gráficos da Cinemática. Revista Brasileira de Ensino de Física, v. 26, n. 2, p. 179 - 184, 2004.

[19] JESUS, V.L.B. e SASAKI, D.G.G., Experimento didático do lançamento horizontal de uma esfera:Um estudo por vídeo análise,Revista Brasileira de Ensino de Física, v. 37, n. 1, 1507, 2015.

[20] BEZERRA JR, A.G., OLIVEIRA, L.P., LENZ, J.A., SAAVEDRA, N., Vídeo análise com o software livre Tracker no laboratório didático de física: movimento parabólico e segunda Lei de Newton, Cad. Bras. Ens. Fís., v. 29, n. Especial 1: p. 469-490, 2012.

[21] AUSUBEL, D.P., Educational psychology - a cognitive view., Holt, Rinehart, USA, 1968.

[22] MOREIRA, M.A., O que é afinal aprendizagem significativa? Aula Inaugural do Programa de Pós-Graduação em Ensino de Ciências Naturais, Instituto de Física, Universidade Federal do Mato Grosso, Cuiabá, MT, 23 de abril de 2010. Aceito para publicação, Qurriculum, La Laguna, Espanha, 2012. 
[23] MOREIRA, M.A., Unidades de enseñanza potencialmente significativas - UEPS Aprendizagem Significativa em Revista/Meaningful Learning Review 1(2), pp. 43-63, 2011.

[24] MOREIRA, M.A., Aprendizagem significativa: a teoria e textos complementares, Livraria da Física, São Paulo, Brasil, 2012.

[25] BARDIN, L., Análise de conteúdo Edições 70, Lisboa, 1995.

[26] SANTOS,R. P., Sequência didática para o ensino de cinemática através de vídeo análise baseada na teoria da aprendizagem significativa, Volta Redonda - RJ, 125 p., Dissertação de Mestrado, MNPEF-Polo 15 - Universidade Federal Fluminense, 2016. Disponível em $<$ http: //www.sistcc. uff.br/sistcc/_tcc/tcc_1481215636.pdf>, último acesso 14/6/2-17.

[27] DIAS, M.A., AMORIM, H.S., BARROS, S.S., Produção de fotografias estroboscópicas sem lâmpada estroboscópica, Cad. Bras. Ens. Fís., v. 26, n. 3: p.492-513, 2009.

[28] PEREIRA, M.V., BARROS, S.S., REZENDE FILHO, L.A.C., FAUTH, L.H.A., Demonstrações experimentais de física em formato audiovisual produzidas por alunos do ensino médio, Cad. Bras. Ens. Fís., v. 28, n. 3: p. 676-692, 2011. 